\section{Spatial Variability of Soluble Solids or Dry-matter Content within Individual Fruits, Bulbs, or Tubers: Implications for the Development and Use of NIR Spectrometric Techniques}

\author{
K.H.S. Peiris, G.G. Dull, R.G. Leffler, and S.J. Kays \\ Department of Horticulture, The University of Georgia, Athens, GA 30602-7273 \\ Additional index words. nondestructive quality evaluation, constituent variability, NIR \\ calibration equations, Malus $\times$ domestica, Cucumis melo, Citrus paradisi, Mangifera \\ indica, Citrus sinensis, Prunus persica, Ananas comosus, Lycopersicon esculentum, \\ Allium cepa, Solanum tuberosum
}

\begin{abstract}
Spatial variation in soluble solids content (SSC) of fruits of apple (Malus $\times$ domestica Borkh. cv. Red Delicious), cantaloupe (Cucumis melo L. Cantaloupensis group), grapefruit (Citrus paradisi Macf. cv. Indian River Ruby Red), honeydew melon (Cucumis melo L. Inodorus group), mango (Mangifera indica L. cv. Hayden), orange (Citrus sinensis L. Osbeck.cv. Valencia), peach (Prunus persica L. Batsch. cv. Windblow), pineapple (Ananas comosus L. Merr. cv. Kew) and tomato (Lycopersicon esculentum Mill.), and of bulbs of onion (Allium cepa $\mathrm{L}$. Cepa group) and in dry-matter content (DMC) of potato (Solanum tuberosum L. cv. Russet Burbank) tubers was measured along three directional orientations (i.e., proximal to distal, circumferentially midway along the proximal to distal axis, and radially from the center of the interior to the outer surface). The pattern and magnitude of constituent variation depended on the type of product and the direction of measurement. Radial and proximal to distal variation was greater than circumferential variation in all the products tested. Honeydew had the highest radial variation with a SSC difference of $6.0 \%$ and a $\mathrm{CV}$ of $22.8 \%$, while tomato displayed lower radial variation with a $\mathrm{CV}$ of $1.0 \%$. Pineapple had a proximal to distal SSC difference of $4.6 \%$ with a $\mathrm{CV}$ of $13.8 \%$, while the difference in tomato was $0.6 \%$ with a $\mathrm{CV}$ of $5.1 \%$. Circumferential variation of $\mathrm{SSC}$ in all products tested was $<2 \%$ with $\mathrm{CV}$ ranging from $1.1 \%$ to $3.8 \%$. The results confirm that considerable constituent variability exists within individual fruit and vegetable organs. This variability may affect the accuracy of calibration equations and their prediction capability. Therefore, withinunit constituent variability should be meticulously assessed when an NIR spectrometric method is being developed for the nondestructive quality evaluation and sorting of a product.
\end{abstract}

Nondestructive techniques are gaining increased attention for quality evaluation and sorting of fruits and vegetables for fresh and processing markets, as well as for the measurement of critical selection traits in plant breeding programs. A wide range of techniques that utilize the interaction of electromagnetic radiation or acoustic waves with matter [e.g., nuclear magnetic resonance (NMR), sonic and ultrasonics, visible light, infrared, and X-ray] have been evaluated for the assessment of internal and/or external quality traits of intact fruits and vegetables (Northeast Regional Agricultural Engineering Service, 1997; Chen and Sun, 1991; Dull,

Received for publication 18 Dec. 1997. Accepted for publication 19 June 1998. The cost of publishing this paper was defrayed in part by the payment of page charges. Under postal regulations, this paper therefore must be hereby marked advertisement solely to indicate this fact.
1986; Finney, 1978; Gunasekaran et al., 1985). These techniques are based on the measurement of optical and/or other physical or chemical properties of the product that display a sufficiently high correlation with the quality trait of interest.

Techniques based on near-infrared (NIR) measurements have been evaluated for the assessment of soluble solids content (SSC) and dry-matter content (DMC) of a number of fruits and vegetables (Birth et al., 1984, and Walsh, 1997; Kawano et al., 1992; Peiris et al., 1997; Slaughter, 1995; Slaughter et al., 1996). Soluble solids content and DMC are important traits used for determining the maturity of certain fruits and vegetables (Kays, 1991), and may influence taste, flavor, nutritional status, and postharvest storage potential of fresh produce, as well as the processing energy requirements, processing costs, product quality, and final product yield of processed food products (Kader and Mitchell, 1989; Sistrunk, 1985; Stevens, 1986). Spectrometric NIR techniques are be1985; Dull et al., 1989a, 1989b, 1992; Guthrie coming increasingly popular for measuring SSC and/or DMC of fresh fruits and vegetables because they can evaluate and sort products more rapidly, inexpensively, and nondestructively than other methods.

The development of an NIR spectrometric technique for assessing a quality trait in a fruit or vegetable product relies upon collecting spectra of the product samples and developing a calibration equation to relate this spectral data with the quality trait ascertained using a standard laboratory method. In NIR quantitative analysis, this is typically called a calibration equation. Calibration equations are developed using various chemometric tools [e.g., multiple linear regression (Hruschka, 1987; Osborne and Fearn, 1986), principal component regression (Cowe and McNicol, 1985), partial least squares regression (Frank et al., 1984; Geladi and Kowalski, 1986), neural networks (Borggaard, 1994; Caudill, 1987; Davies, 1994; Lawrence, 1994; McClure et al., 1992)].

Techniques such as X-ray, NMR, acoustics, and ultrasonics generally assess the internal quality of the entire product unit during sample measurement. However, when NIR spectrometric techniques are used for the internal quality assessment of fruits and vegetables, optical data from the samples are obtained using interactance or body transmittance (Chen and Nattuvetty, 1980; Conwey et al., 1984; McClure, 1994), where both the input and collecting optics are placed against the sample surface. Such a configuration avoids specular and diffuse reflectance components of input energy that do not confer information on the characteristics of the internal tissues. Because of the rapid attenuation of NIR radiation with increasing path length in optically dense, moist materials, such as fresh fruits and vegetables, the collecting optics often must be placed close to the input optics to achieve a strong signal-to-noise ratio. This method of scanning, therefore, assesses only a small portion of the each individual product unit. The fraction of the sample scanned depends upon the size of the unit, the intensity of the energy source, the optical characteristics of the tissue, and the size and positioning of the input and collecting optics.

Many quality attributes vary among individual product units, creating the need for grading and sorting. Variations in the levels of such attributes may also exist within an individual product unit. If there is little or no constituent variability within units, as in ground food materials used in NIR reflectance methods, the volume or the location of the area scanned will not influence the calibration equation. However, if variability exists, the development of an accurate calibration equation and evaluation of its performance require more care. The error (i.e., the difference in actual constituent value between the scanned area and that determined by the standard method for the product sample) introduced in calibration model development leads to higher prediction errors than those obtained when the sample is uniform throughout. Therefore, one must be aware of the pattern and magnitude of 
constituent variability within the sample and the implications of such variability on development and use of a calibration equation for nondestructive quality evaluation.

The objectives of this study were to: 1) determine the variability of soluble solids or dry-matter content of edible tissue along the proximal to distal direction, circumferentially midway between the proximal and distal ends, and radially from the center of the interior to the outer surface of individual product units for a number of fruits and vegetables where the potential exists for developing NIR-based quality assessment techniques; and 2) discuss the influence of such variability within the product unit in relation to the development of an accurate calibration equation for NIR spectrometric techniques.

\section{Materials and Methods}

Fruit and vegetable products were either grown at The Univ. of Georgia Horticulture farm or procured from Dekalb Farmer's Market, Atlanta. The products were allowed to equilibrate to laboratory temperature $\left(20^{\circ} \mathrm{C}\right)$ before analysis. For larger fruit (i.e., apple, cantaloupe, honeydew, mango, and pineapple), tissue samples were obtained using a $10-\mathrm{mm}$ diameter cork borer, perpendicular to the surface from the proximal to distal ends. The peel was removed from these cylinders using a razor blade, and the tissue trimmed to $2-\mathrm{cm}$ lengths from the outer end. For the measurement of circumferential variability in SSC, sample cores were taken equatorially and midway between the proximal and distal ends. Radial distribution of SSC in sample cores taken midway between proximal and distal ends was determined after separating the core into a number of segments of uniform length. For tomatoes, the entire fruit was sliced into five uniform, transverse sections. Circumferential SSC variability was measured by cutting the fruit into six longitudinal segments around the proximal-distal axis. Radial variability of tomato fruit was measured by analyzing pericarp and locules + placenta portions of a 1-cm-thick transverse slice made midway between the proximal and distal ends. Grapefruit, orange, and peach fruits were cut into 1-cm-thick slices along the proximal to distal axis, and each slice was divided into uniform-sized segments for measuring proximal to distal SSC variability. Circumferential variability was measured by making a $1-\mathrm{cm}$ wide transverse slice midway between the proximal and distal ends and dividing it into equal-sized segments. Radial distribution was measured by dividing a transverse slice taken midway on the proximal to distal axis of the fruit into equal-length segments. Because of their flat, ovate shape, only two locations in onion bulbs were sampled, using a 9-mmdiameter cork borer, to measure SSC variability along the proximal-distal axis. For circumferential variability, four cores (9-mm diameter) were taken around the equator midway between the proximal and distal ends of the bulb. Radial distribution was measured using sample cores taken midway between the proxi- mal and distal ends of the bulb and separating them into three equal-length segments from the interior to the surface. Potato tubers were cut into four sections across and around the proximal (stolon-end) to distal axis for measuring proximal to distal and circumferential variability, respectively. For the measurement of radial distribution of DMC, 10-mm-diameter cores were removed from the center of the tuber, and DMC was determined for the core and peripheral tissues separately.

The DMC of potato was determined by freeze drying. Tomato slices were ground using a mortar and pestle to prepare the sample for SSC analysis. The juice samples of other product samples were collected using a garlic press and the SSC of the juice was measured using a temperature-compensated refractometer (ABBE-3L; Bausch and Lomb, Rochester, N.Y.) at $20^{\circ} \mathrm{C}$. Eight samples were measured for each axis in each product. Means and standard errors of means were calculated for the SSC or DMC data for each segment in each direction. The coefficient of variation of the constituent was computed for each direction of measurement as well as for the entire unit of product.

\section{Results and Discussion}

The mean and standard errors of the DMC for potato and the SSC for all other products of tissue samples taken along the three directional orientations described above are shown in Figs. 1-3. Since there was not a reference

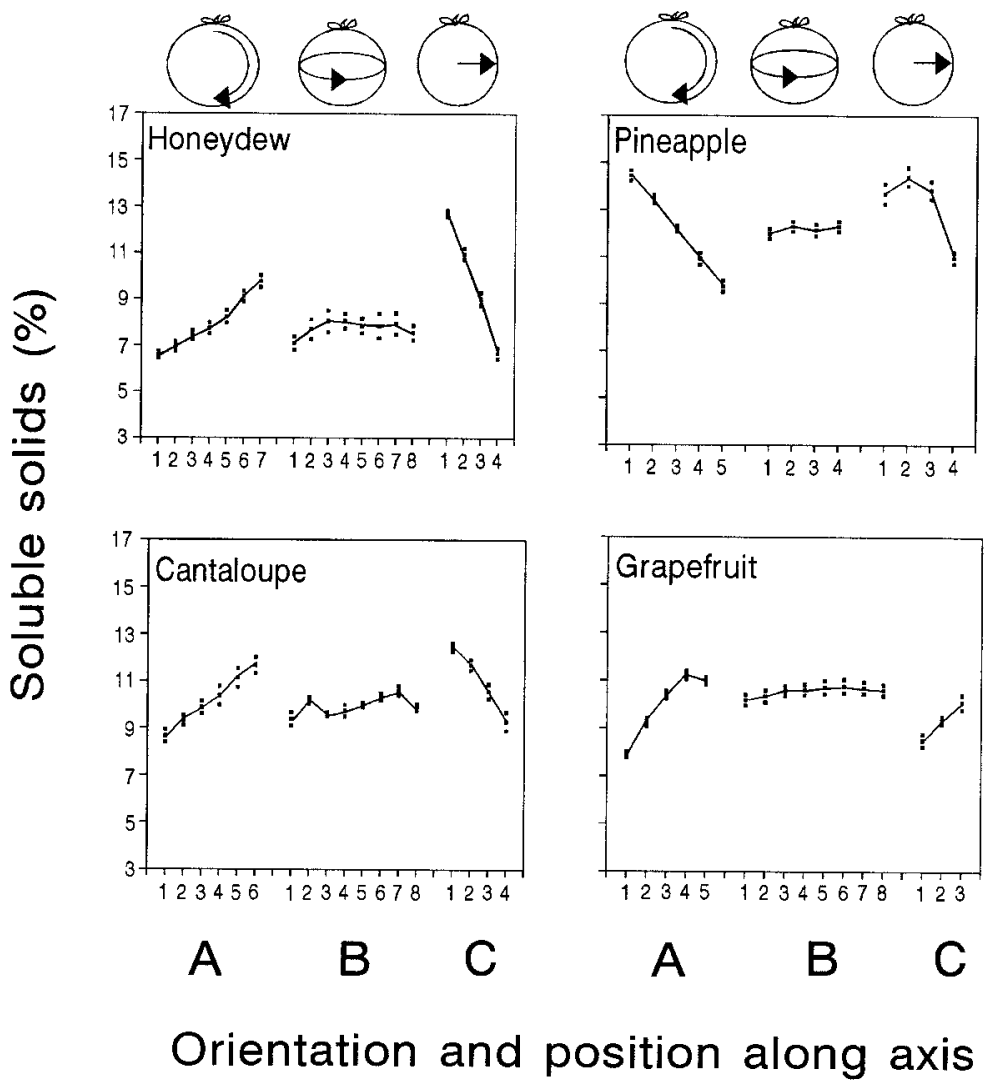

Fig. 1. Soluble solids content variability within honeydew melon, pineapple, cantaloupe, and grapefruit in (A) proximal to distal, (B) equatorial, and (C) radial directional orientations. Numbers in X-axis along the directional orientations indicate consecutive sections.

position for circumferential data, constituent values were plotted with the lowest value for each individual replicate on the left. To allow comparison of values among species, SSC data were plotted using the same scale (3\% to $17 \%$ ) for all products.

The SSC of apple, cantaloupe, honeydew, and tomato fruit (first segment of each figure) increased linearly along the proximal-distal axis. Similarly, citrus (orange and grapefruit) SSC increased gradually, then declined slightly toward the distal end. In contrast, pineapple SSC was lowest at the distal (crown) end and increased sharply toward the proximal (peduncle) end. Onion SSC was highest at the base and lowest at the apex. Mango had a higher SSC at the proximal than at the distal end. The SSC of peach declined slightly toward the distal end and then increased slightly. Potato had a higher dry-matter content at the proximal than at the distal end.

The second segment in each figure displays the variability in SSC circumferentially at the center of each product. Grapefruit, orange, mango, onion, and tomato displayed a single wave distribution, the SSC increasing and then decreasing, such that values for one side were comparatively higher than for the other side. The flatter the curve, the smaller the variation. Peach, honeydew, and cantaloupe displayed two waves, indicating that two sides of the fruit had higher SSC and were separated by regions with low SSC.

For most fruit the SSC increased toward the outer surface (Figs. 1C, 2C, 3C). In mel-
HortScience, Vol. 34(1), February 1999 

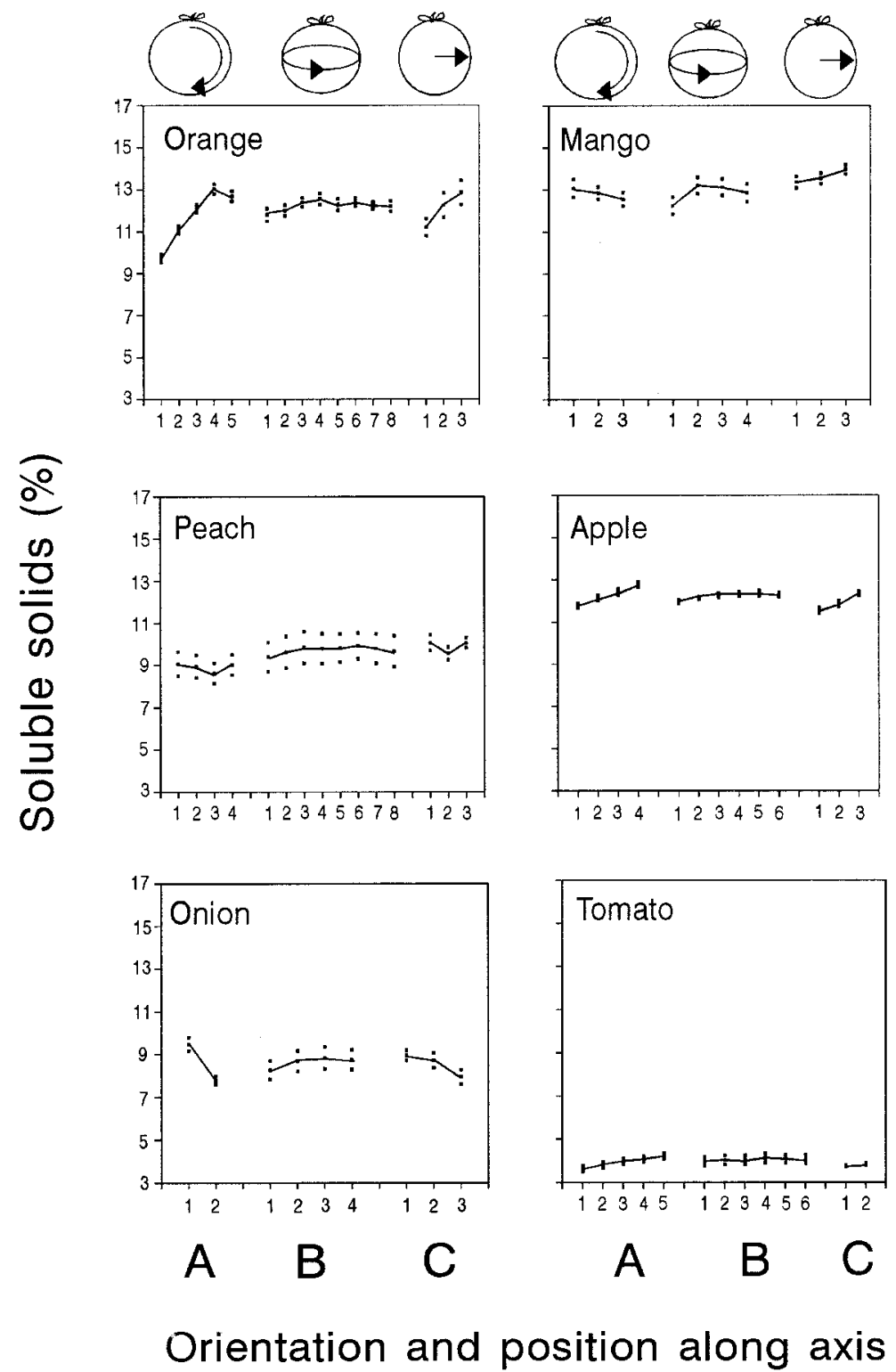

Fig. 2. Soluble solids content variability within orange, mango, peach, apple, onion, and tomato in (A) proximal to distal, (B) equatorial, and (C) radial directional orientations. Numbers in X-axis along the directional orientations indicate consecutive sections.

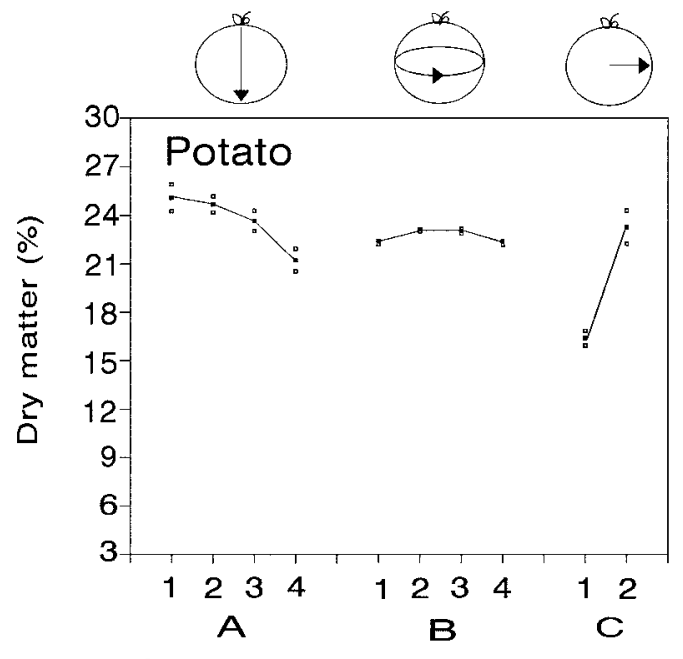

Orientation and position along axis

Fig. 3. Dry-matter content within potato (A) proximal to distal, (B) equatorial, and (C) radial directional orientations. Numbers in $\mathrm{X}$-axis along the directional orientations indicate consecutive sections. 
opment of the NIR calibration equation. For example, assume that the SSC in a honeydew fruit with a length of $26 \mathrm{~cm}$ ranges from $6.6 \%$ to $9.8 \%$ from the proximal to distal ends, or an average SSC gradient of $0.12 \%$ per centimeter along the proximal-distal axis. A 3.5-cm-thick slice from the same fruit with a range of $12.7 \%$ to $6.7 \%$ in SSC from the inner to the outer surface has a gradient of $1.71 \%$ per centimeter. The radial gradient is $\approx 14$ times as high as the distal to proximal gradient. When a core sample is used for the determination of SSC, the value measured will depend strongly upon what part of the core is used. Likewise, a tomato $8-\mathrm{cm}$ long with a difference in SSC of $0.6 \%$ along the proximal to distal axis has a gradient of $0.08 \%$ per centimeter. Though this is smaller and therefore seems less significant in absolute terms when compared with the variability found within and among the commercial processing tomato cultivars (i.e., often $2 \%$ to $2.5 \%$ difference within a single cultivar and $<5 \%$ among commercial cultivars), the variability along the proximal to distal axis within a single fruit represents $24 \%$ to $30 \%$ of the total variability found within a cultivar. Under such circumstances, a small error introduced into the calibration equation can influence its prediction performance.

Given that an accurate calibration equation has been developed for a product that takes into account the influence of constituent variability, prediction errors can also be encountered during its application in the evaluation of a product. Information on constituent variability within product units is helpful in minimizing such errors and arriving at an accurate estimate of the constituent value for the product.

Several options can be adopted to minimize errors introduced into calibration equations and to reduce prediction errors. One option is to increase the volume of sample used for scanning by employing stronger energy sources and changing instrumental configurations in relation to the distance between input and output optics. Care should be taken, however, not to damage the product due to the intense heat generated by high intensity energy sources. This could be achieved by using instruments fitted with spectrometers with higher scanning frequencies and wider input and collection optics. The appropriate intensity/distance relationship should be used to obtain smooth spectra rapidly (i.e., within a few seconds). When tissue samples are taken for constituent determination, samples should be representative of the depth of NIR penetration, especially for products with a high constituent gradient.

Another option is to scan individual product units at one or several locations that collectively represent the average constituent level for the entire unit. Scanlon et al. (1997) studied the best region in potato tubers for taking NIR scans in order to predict dry-matter content of the whole tuber. They showed that the values for the center outside section of the tuber were most closely correlated $\left(r^{2}>0.93\right)$ with dry-matter content, allowing an accurate prediction of whole tuber dry matter. Slaugh- ter et al. (1996) took scans of tomato at different locations (equatorial and blossom end) and developed calibration equations from specific locations to predict SSC of fruit based on spectra taken at other locations. Higher standard error of prediction (SEP) values $(0.53 \%$ to $0.87 \%$ ) were observed when calibration equations developed from equatorial scans were used to predict SSC of fruit from spectra taken at the distal end. Calibration equations developed from equatorial scans had much lower SEP values $(0.37 \%$ to $0.43 \%)$ when fruit SSC was predicted based on equatorial scans. These results show that the presence of constituent variability within a product unit significantly affects the accuracy of calibration equations and their predictability, and that the accuracy of estimations could be enhanced by taking spectra from regions representing the whole product's constituent value.

\section{Conclusions}

Considerable variability existed in SSC and/or DMC within individual organs tested in this study. The magnitude of this variability depended upon the type of product and the directional orientation along which the measurements were made. Variability within single units of product influences the prediction capability of the NIR calibration equations developed, especially when small volumes of sample are scanned to obtain the optical data for products having significant constituent variability. The effect of this variability is more pronounced when within unit variability is substantial relative to among unit variability. Regardless of the manner in which the samples are scanned and calibrations developed, some error due to the inherent constituent variability remains when NIR spectrometric techniques are developed for intact fresh produce. Therefore, when such a method is being developed for a particular product, the variability in the constituent of interest must be comprehensively assessed to maximize the accuracy of the calibration equation and improve its prediction performance. The way in which constituent variability is dealt with to improve the calibration equation will vary from product to product.

\section{Literature Cited}

Berry, S.Z., M.R. Uddin, W.A. Gould, A.D. Bisges, and G.D. Dyer. 1988. Stability in fruit yield, soluble solids and citric acid of eight machineharvested processing tomato cultivars in northern Ohio. J. Amer. Soc. Hort. Sci. 113:604-608.

Birth, G.S., G.G. Dull, J.B. Magee, H.T. Chan, and C.G. Cavaletto. 1984. An optical method for estimating papaya maturity. J. Amer. Soc. Hort. Sci. 109:62-66.

Birth, G.S., G.G. Dull, W.T. Renfroe, and S.J. Kays. 1985. Nondestructive spectrophotometric determination of dry matter in onions. J. Amer. Soc. Hort. Sci. 110:297-303.

Borggaard, C. 1994. Modeling non-linear data using neural networks regression in connection with PLS or PCA. Spectroscopy Europe. 6(3):2127.

Caudill, M. 1987. Neural networks primer. Artificial Intelligence Expert 2(12):46-52.
Chen, P. and V.R. Nattuvetty. 1980. Light transmittance through a region of an intact fruit. Trans. Amer. Soc. Agr. Eng. 23:519-522.

Chen, P. and Z. Sun. 1991. A review of non-destructive methods for quality evaluation and sorting of agricultural products. J. Agr. Eng. Res. 49:8598.

Conwey, J.M., K.H. Norris, and C.E. Bodwell. 1984. A new approach for the estimation of body composition: infrared interactance. Amer. J.Clin. Nutr. 40:1123-1130.

Cowe I.A. and J.W. McNicol. 1985. The use of principal components in the analysis of near infrared spectra. Appl. Spectroscopy 39:257266

Davies, A.C.M. 1994. The year of neural network. Spectroscopy Europe 6(1):27-28.

Dull, G.G. 1986. Nondestructive evaluation of quality of stored fruits and vegetables. Food Technol. 40:106-110.

Dull, G.G., G.S. Birth, R.G. Leffler. 1989a. Use of near infrared analysis for the nondestructive measurement of dry matter in potatoes. Amer. Potato J. 66:215-225.

Dull, G.G., G.S. Birth, D.A. Smittle, and R.G. Leffler. 1989b. Near infrared analysis of soluble solids in intact cantaloupe. J. Food Sci. 54:393395.

Dull, G.G., R.G.Leffler, G.S. Birth, andD.A. Smittle. 1992. Instrument for nondestructive measurement of soluble solids in honeydew melons. Trans. Amer. Soc. Agr. Eng. 35:735-737.

Finney, E.E. 1978. Engineering techniques for nondestructive quality evaluation of agricultural products. J. Food Protection. 41:57-62.

Frank, I.E., J. Feikema, N. Constantine, and B.R. Kowalski. 1984. Prediction of product quality from spectral data using the partial least squares method. J. Chem. Info. Comput. Sci. 24:20-24.

Geladi, P. and B.R. Kowalski. 1986. Partial leastsquares regression: A tutorial. Anal. Chim. Acta. 185:1-17.

Gunasekaran, S., M.R. Paulsen, and G.C. Shove. 1985. Optical methods for nondestructive quality evaluation of agricultural and biological materials. J. Agr. Eng. Res. 32:209-241.

Guthrie, J. and K. Walsh. 1997. Non-invasive assessment of pineapple and mango fruit quality using near infrared spectroscopy. Austral. J. Expt. Agr. 37:253-263.

Hruschka, W.R. 1987. Data analysis: Wavelength selection methods, p. 35-55. In: P. Williams and K. Norris (eds.). Near-infrared technology in the agricultural and food industries. Amer. Assn. Cereal Chem., St. Paul, Minn.

Kader, A.A. and F.G. Mitchell. 1989. Maturity and quality, p. 191-196. In: J.H. LaRue and R.S. Johnson (eds.). Peaches, plums and nectarines: Growing and handling for fresh market. Univ. Calif. Div. Agr. Nat. Res. Pub. 3331.

Kawano, S., T. Sato, and M. Iwamoto. 1992. Determination of sugars in Satsuma orange using NIR transmission, p. 387-393. In: I. Murray and I.A. Cowe (eds.). Making light work: Advances in near infrared spectroscopy. VCH, Weinheim, N.Y.

Kays, S.J. 1991. Postharvest physiology of perishable plant products. Van Nostrand Reinhold, New York.

Lawrence, J. 1994. Introduction to neural networks: Design, theory and applications. California Scientific Software Press, Nevada City, Calif.

McClure, W.F. 1994. Near-infrared spectroscopy. p. 13-57. In. R.H. Wilson. (ed.). Spectroscopic techniques for food analysis. VCH, Weinheim, N.Y.

McClure, W.F., M. Hana, and J. Sugiyama. 1992. Neural networks in NIR spectroscopy, p. 200209. In: I. Murray and I.A. Cowe (eds.). Making 
light work: Advances in near infrared spectroscopy. VCH, Weinheim, N.Y.

Northeast Regional Agricultural Engineering Service. 1997. Sensors for nondestructive testing: Measuring the quality of fresh fruits and vegetables. Proc. Intl. Conf. Sensors for Nondestructive Testing: Measuring the Quality of Fresh Fruits and Vegetables. Northeast Reg. Agr. Eng. Serv., Ithaca, N.Y.

Osborne, B.G. and T. Fearn. 1986. Near-infrared spectroscopy in food analysis. Wiley, N.Y.

Peiris, K.H.S., G.G. Dull, R.G. Leffler, and S.J. Kays. 1997. Nondestructive determination of soluble solids content of peach by near infrared spectroscopy. p. 77-87. In: Proc. Intl. Conf. Sensors for Nondestructive Testing: Measuring the Quality of Fresh Fruits and Vegetables. Northeast Regional Agricultural Engineering Service, Ithaca, N.Y.

Scanlon, M.G., M.K. Pritchard, and L.R. Adam. 1997. NIR analysis of dry matter and sugars in whole potato tubers, p. 88-100. In: Proc. Intl. Conf. Sensors for Nondestructive Testing: Measuring the Quality of Fresh Fruits and Vegetables. Northeast Reg. Agr. Eng. Serv., Ithaca, N.Y.

Sistrunk, W.A. 1985. Peach quality assessment: Fresh and processed, p. 1-46. In: H.E. Pattee (ed.). Evaluation of quality of fruits and vegetables. AVI, Westport, Conn.

Slaughter, D.C. 1995. Nondestructive determination of internal quality in peaches and nectar- ines. Trans. Amer. Soc. Agr. Eng. 38:617-623.

Slaughter, D.C., D. Barrett, and M. Boersig. 1996. Nondestructive determination of soluble solids in tomatoes using near infrared spectroscopy. J. Food Sci. 61:695-697.

Stevens, M.A. 1986. Inheritance of tomato fruit quality components. Plant Breeding Rev. 4:273311.

Stevens, M.A., A.A. Kader, and M.A. Holton. 1977. Intercultivar variation in composition of locular and pericarp portions of fresh market tomatoes. J. Amer. Soc. Hort. Sci. 102:689-692.

Williams, J.W. and W.A. Sistrunk. 1979. Effect of cultivar, irrigation, ethephon and harvest date on the yield and quality of processing tomatoes. J. Amer. Soc. Hort. Sci. 104:435-439. 